\title{
AMSSM: increasingly valuable for primary care sports and exercise medicine physicians
}

\author{
Karim M Khan, ${ }^{1}$ Babette M Pluim²
}

\begin{abstract}
The American Medical Society for Sports Medicine (AMSSM) is a jewel in the global primary care sports and exercise medicine crown. In a very competitive market for their society dollars, US primary care physicians vote overwhelmingly for AMSSM, giving it a landslide victory. Membership is (almost) universal because of the benefits such as education and research support combined with networking opportunities. Conference attendance climbs year over year. Quality sponsors such as Donjoy (DJO) add substantial value (eg, travelling fellowship programme). Membership is available for less than the price of a kid's phone (US\$400). The organisation serves as a role model, a 'success story'. And as health reform rolls though the USA, the support of AMSSM has never been more critical for sports physicians (ominous background music..., see 'Chris Madden' below).
\end{abstract}

\section{SIX WAYS THAT AMSSM ADDS VALUE -FOR PHYSICIANS AND PATIENTS}

1. Strength in numbers: AMSSM is a nationwide sports and exercise medicine interest group exclusively dedicated to US primary care sports physicians. No need to get primary care on the agenda-primary care sports and exercise medicine is the agenda. As the medical landscape transforms in the USA, shared wisdom becomes evermore critical. What changes are coming via the Centre for Medicare/Medicaid Services (CMS, get used to this acronym)? How can I turn threat into opportunity? Do not call Ghostbusters - join AMSSM and listen/participate. AMSSM is there for you.

2. Education: AMSSM provides education in at least six major categories. These include AMSSM members who are

\footnotetext{
${ }^{1}$ Aspetar Orthopaedic and Sports Medicine Hospital, Doha, Qatar; ${ }^{2}$ Medical Department, Royal Netherlands Lawn Tennis Association (KNLTB), Amersfoort, The Netherlands

Correspondence to Dr Babette M Pluim, Medical Department, Royal Netherlands Lawn Tennis Association (KNLTB), Amersfoort 3821 BT, The Netherlands; b.pluim@knltb.nl
}

Fellowship Directors across the USA, the Annual Meeting programme and the rich workshops available there, AMSSM's primary care education materials including case reports on the website, a branded textbook and a suite of clinical guidelines (eg, for concussion) and curriculum (eg, ultrasound training) for sports and exercise medicine.

3. The 2015 Annual Meeting 14-19 April. Concussion, Return to Play, Exercise is Medicine, Ulnar Collateral Ligament Injury, Orthobiologics for Degenerative Joint Disease, Imaging of Complex Groin Pain in Athletes and Medical Education are just snippets. You want names? Howzabout Guskiewicz, Dvorak, Bahr, Myer, Harmon, Hutchinson, Patricios, Weir, Wilk and Lionel Messi, just for starters? OK, one of them will NOT be a starter but I made you look ('9 truths and a lie'great game) ("Which NCAA team is Lionel Messi the doctor for? I don't get this guy"). And the Sports Ultrasound Instructional Workshop. Kudos to AMSSM leads Irfan Asif and incoming President Jon Divine. Important part or the AMSSM mission. Check. Big check mark. Home run, touchdown, hat-trick, dunk in overtime, buzzer-beating Hail Mary and Khalas!

4. Research is fundamental to defining our discipline and the AMSSM provides leadership through coordination (avoid duplication, harness synergies), education (how to do it) and, increasingly, seed funding (via the AMSSM Foundation). Thus, the AMSSM fosters research and it facilitates members' access to relevant research by providing access to BJSM (24 issues annually, really? that seems like a lot?), the Clinical Journal of Sport Medicine (six issues annually) and Sports Health: A Multidisciplinary Approach (six issues annually).

5. Practice tips and career advice: Success as a physician requires more than 'content knowledge', and AMSSM is a community of mentors. The camaraderie means young physicians get mentored (Is that a word?-sounds dodgy) formally and informally. A social event conversation on the eve of the Annual Meeting in Cancun provided one fellow with a critical connection that led to her landing a college job opportunity. These interactions are ubiquitous at Annual Meetings and deliberately fostered by AMSSM leadership. From the outside, the formula looks like (i) invest in the best talent for conference programmes, (ii) use one hotel and include social events within a very reasonable registration fee, (iii) schedule formal networking events (eg, Fellowship Forum, Team Physician Breakouts, Special Interest Breakouts), (iv) leave 'unscheduled time' for the magic to happen and (v) lead by example-be great and have fun!

6. Advocacy - the 'union' role: I appreciate the important distinction between the physicians 'guild' (AMSSM in this case) and the licensing bodies (statebased in the USA). And without getting into the merits/demerits of labour unions, Steinbeck's Grapes of Wrath and Mitt Romney's "we should have let Detroit go bankrupt," the AMSSM supports primary care sports and exercise medicine physicians in grappling with the 'business' side of medicine.

President Chris Madden's leadership relating to US Health Reform and his From the Sideline columns are a Must Read. This is where the scary soundtrack gets louder. Clinicians who do not adapt their practice and the Continuing Medical Education (CME) with new guidelines risk losing their certifications, which may threaten their practices. You will risk being sidelined or penalised by payer networks and patients may find it difficult to access you. Hence the music from Psycho. Who's the Erin Brockovich taking care of you? You must take personal responsibility but AMSSM provides expertise and resources; it provides a forum to share the pros and cons of various settings in which to practice sports and exercise medicine, advice on quality initiatives, billing, marketing and compensation considerations. You will hear more.

\section{AMSSM AND THE SPORTS MEDICINE REVOLUTION IN ULTRASOUND}

In this issue read the TWO ultrasound consensus statements, learn how ultrasound can be used to assess fractures as well as identify neuropathies. Listen to the ultrasound podcast featuring AMSSM Dr Ken Mautner (host), Dr John DiFiori and Dr Jonathan Finnoff. They explain why the term sports ultrasound is important and accurate-sports medicine needs much more than mere musculoskeletal ultrasound alone. Thanks to issue 


\section{Warm up}

editors Dr Ken Mautner and Dr Mederic Hall and all AMSSM authors who contributed.

This AMSSM issue vivifies the benefit of the member society (AMSSM in this case)-BJSM partnership. It is relevant, innovative and educational, using multimedia/channels (ie, online text, audio, video, social media promotion). A Hollywood ending for sports medicine for those who address the potential To cite Khan KM, Pluim BM. Br J Sports Med threats.

\section{Competing interests None.}

Provenance and peer review Not commissioned; internally peer reviewed.
2015;49:137-138.

Accepted 23 December 2014

Br J Sports Med 2015;49:137-138. doi:10.1136/bjsports-2014-094555 